\title{
Investigating the effect of Alcohol Brief Interventions within Accident \& Emergency departments using a data informatics methodology
}

Alex Baldacchino $^{1 *}$ : Professor of Medicine, Psychiatry and Addictions. Email: $\underline{\operatorname{amb} 30 @ s t-}$ andrews.ac.uk

Louise O'Rourke ${ }^{1}$ : NHS Education Scotland (NES) Health Psychology trainee. Email: lou.orourke90@gmail.com

Gerry Humphris ${ }^{1}$ : Professor of Health Psychology. Email: gmh4@ st-andrews.ac.uk

${ }^{1}$ St Andrews Medical School, Division of Population and Behavioural Science, University of St Andrews, North Haugh, St Andrews, Fife, KY16 9TF, Scotland, United Kingdom.

*Corresponding Author Professor Alex Baldacchino, St Andrews Medical School, Division of Population and Behavioural Science, University of St Andrews, North Haugh, St Andrews, Fife, KY16 9TF, Scotland. Email: amb30@st-andrews.ac.uk 


\title{
Investigating the effect of Alcohol Brief Interventions within Accident \& Emergency departments using data informatics methodology
}

\begin{abstract}
Background

Alcohol Brief Interventions (ABI) have been implemented throughout Scotland since 2008 aiming to reduce hazardous drinking through a Scottish government funded initiative delivered in a range of settings including Accident and Emergency (A\&E) departments.
\end{abstract}

\section{Purpose}

To study the extent to Alcohol Brief Interventions (ABI) is associated with later health service use.

\section{Method}

An opportunistic informatics approach was applied. A unique patient identifier was used to link patient data with core datasets spanning two years previous and two years post ABI. Variables included inpatient attendance, outpatient attendance, psychiatric admissions, A\&E attendance and prescribing. Patients $(\mathrm{N}=1704)$ who presented at $\mathrm{A} \& \mathrm{E}$ departments who reported an average alcohol consumption of more than 8 units daily received the ABI. Fast Alcohol Screening Test (FAST) was used to assess patients for hazardous alcohol consumption. Multilevel linear modelling was employed to predict post-intervention utilisation using pre-ABI variables and controlling for person characteristics and venue. 


\section{Results}

Significant decrease in A\&E usage was found at one and two years following the ABI intervention. Previous health service use was predictive of later service use. A single question (Item 4) on the FAST was predictive of A\&E attendance at one and two years.

\section{Conclusions}

This investigation and methodology used provides support for the delivery of the ABI. However it cannot be ascertained as to whether this is due to the ABI, or simply as a result of making contact with a specialist in the addiction field.

Keywords Alcohol Brief Intervention Screening Informatics 


\subsection{Introduction}

Alcohol consumption in the European Union remains the highest in the world (World Health Organisation 2010) and is regarded a major risk factor for premature mortality (Rehm et al. 2011). In 2014 in Scotland, $41 \%$ of men drank more than the recommended 3-4 units on their heaviest drinking day, and a third (33\%) of women drank more than their recommended 2-3 daily units (The Scottish Health Survey 2014). Of the 35,926 alcohol-related discharges in Scotland during 2012/13, 92\% resulted from an emergency admission (ISD Scotland, 2014). Consequently, recognising approaches to reduce alcohol misuse is vital, as it is estimated to cost the NHS $£ 3.5$ billion (Public Health England 2013) and more specifically, $£ 110.5$ million to NHS Scotland (Scottish Trauma Audit Group, 2006).

\subsection{Screening tool}

The social and economic cost of the effect of alcohol misuse has prompted attempts to identify via a screening tool those at risk of harmful effects of excessive alcohol consumption. The AUDIT (Alcohol Use Disorders Identification Test) 10-item questionnaire was originally designed for use in primary services (World Health Organisation 2001), successfully identifying those who are at current risk of harmful, dependent drinking (Saunders et al. 1993; Thomas et al. 2014), or those who consume alcohol at a lower threshold than harmful and dependent drinkers. However, this particular tool is time consuming, and shorter screening methods are necessary for implementation within busy clinical settings. Alternatively the Fast Alcohol Screening Test (FAST) was developed, consisting of four questions that contain elements of the AUDIT questionnaire (Supplementary Table 1). Individuals scoring above three out of a possible sixteen are considered hazardous drinkers (Hodgson et al. 2002). Taking approximately 20 seconds to complete, the instrument is deemed to be substantially quicker than other current measures, 
as over $50 \%$ of patients screened in A\&E can be identified as either a hazardous drinker or not by asking the initial question (Hodgson et al. 2002).

\subsection{Brief intervention}

Alcohol Brief Interventions (ABIs) have been delivered throughout Scotland in recent years, aiming to reduce hazardous drinking due to a Scottish Government funded initiative through a policy governed 'HEAT' standard (Scottish Government 2014). HEAT targets are set out by NHS Scotland and the Scottish Government's Health Directorates, ensuring services are constantly monitored and improved. There are four groups of HEAT targets: (i) Health Improvement; (ii) Efficiency; (iii) Access to Treatment and (iv) Treatment. The intervention itself is a short conversation 'aiming in a non-confrontational way to motivate individuals to think about and/or plan a change in their drinking behaviour in order to reduce their consumption and/or their risk of harm' (Scottish Government, 2015). ABIs use specific techniques for helping people to change their behaviour and draw on the ethos of Motivational Interviewing (MI) (Dunn et al. 2001) and the FRAMES (Feedback, Responsibility, Advice, Menu, Empathic, Self-efficacy) approach (Bien et al. 1993). There is no strong evidence to suggest that multiple ABIs, or repeat sessions, are more effective in reducing alcohol consumption than single sessions (Kaner et al. 2007).

If the individual is deemed to be consuming harmful levels of alcohol after having undergone screening, it is advised a referral is made for further treatment. This is in accordance with the SBIRT principle (Babor et al. 1986, 2007) in addressing alcohol use disorders (AUD) in primary health care, whereby the following steps are recommended: screening, brief interventions or advice for people with hazardous and harmful drinking, and referral to treatment for those who have more serious signs of substance dependence. 
Although evidence concludes that early identification and interventions are effective in reducing hazardous and harmful drinking, compared to control conditions in healthcare environments especially primary care (Heather, 2011; Kaner et al. 2007; Kaner, 2016; O Donnell et al. 2014) and hospital wards (McQueen et al. 2011) little effectiveness has been found within A\&E departments (Havard et al. 2008; Nilsen et al. 2008; Woynar and Jacubczyk, 2014). As emergency departments receive a substantial number of individuals presenting with alcohol related injuries (Cherpitel, 2007), it is important that this particular setting is analysed, and whether or not this point of contact is successful in promoting longer term health behavioural change. Reviews report that most studies exploring ABI effectiveness at A\&E settings were assessed up to no more than 12 months after the actual intervention (Woynar and Jacubczyk, 2014). This can better assessed using a proxy measure, such as health care utilisation. It is argued that maintaining behaviour is achieved through self-regulatory skills and strategies, whereby efforts are undertaken in order to alter one's behaviour (Carver and Scheier, 1998). In particular, implementation intentions have been demonstrated as an effective self-regulatory strategy influencing performance of behaviour and habit performance (Gollwitzer and Sheeran, 2006). This has been evidenced in brief interventions addressing excessive alcohol consumption, as prompting self-recording and prompting commitment from the patient is associated with greater intervention effectiveness (Michie et al. 2012).

A systematic review and meta-analysis indicated that alcohol screening and brief interventions in primary care and emergency departments reduce the need for later emergency department visits, but little effect was found on later inpatient or outpatient medical care (Bray et al. 2011). However, it was noted that there was inconsistent and 
incomplete reporting by many publications on health care utilisation outcomes, and approximately half of the studies did not measure outpatient utilisation (Bray et al. 2011). In a recent multicentre pragmatic cluster randomized controlled trial within UK A\&E departments ABI was considered as the more acceptable and less expensive clinical intervention (Drummond et al. 2014).

The aim of this study is to investigate, using a data informatics methodology, the association, if any, of administering ABI on patients' future use of health services (2 years) compared with their historical utilisation.

\subsection{Material and Methods}

\subsection{Study area}

The study was conducted in a mixed urban area, with a population of approximately 354,600 geographically situated in the South Eastern Region of Scotland, United Kingdom.

\subsection{Data linkage}

Individual data were anonymised and stored within the Health Informatics Centre (HIC) based Safe Haven, which is a restricted and secure IT environment allowing delegated researchers to $\log$ on remotely to a secure server located within HIC. The research was conducted in accordance with their operational procedures (School of Medicine, University of Dundee, 2015).

The CHI (Community Health Index) number, a unique patient identifier, was used to link healthcare records to a number of other datasets held within the HIC. Core datasets include: medical outpatient attendance (SMR00) and inpatient admissions (SMR01), psychiatric 
inpatient admissions (SMR04), A\&E attendance and community dispensing records were used as proxy measures for patient health utilisation. These healthcare records were linked two years previously to the delivery of the ABI and two years after, in order to gain a comparison of individual health outcomes before and after the intervention. Socioeconomic deprivation was measured at the neighbourhood level using the Scottish Index of Multiple Deprivation (SIMD) (SIMD, 2012), in order to establish the socioeconomic status for each patient. Scores ranked from living in the most deprived areas (1), to living in the most affluent areas (10) (Figures 1 and 2).

\subsection{Recruitment}

\subsubsection{Screening for hazardous drinking}

The FAST tool (Hodgson et al. 2002) was implemented as part of the ABI, in order to screen for hazardous drinking. Having undergone validity testing in primary care, the FAST has demonstrated sufficient reliability, possessing a Cronbach's alpha of .77 (Hodgson et al. 2002). The Fast Alcohol Screening Test (FAST) questionnaire is the most sensitive and accurate screening tool in identifying alcohol misuse within accident and emergency department (Public Health England, 2013). Individuals were approached to receive the ABI if they were in an intoxicated state, or reported an average alcohol consumption of 8 units daily (Supplementary Table 1). Index attendance was excluded from the pre-intervention A\&E attendance count.

\subsubsection{Intervention using ABI}

Once identified the individuals will be asked to be seen by a specialist addiction nurse (Platt et al.2016) within the A\&E Department to provide in situ a time-limited structured non 
confrontational conversation about alcohol consumption that seeks to motivate and support an individual to think about and/or plan a change in their drinking behaviour.

\subsection{Analysis}

SPSS version 22.0 and STATA version 13.0 used to analyse the data. Changes in patient health service utilisation (i.e. comparable use of admissions or out- and in-patient services) post-ABI were assessed using paired sample t-tests (equal group variances not assumed). Logistic regression using maximum likelihood estimation was used to predict $\mathrm{A} \& \mathrm{E}$ attendance (and health service use in other reported analyses) following intervention delivery, with healthcare records (e.g., outpatient attendance, inpatient admissions) as predictors. Multi-level modelling using the 'xtmelogit' procedure within STATAv13 was applied to control for clustering effects of the two A\&E sites. An alpha level ( 2 sided) of 0.05 was adopted for all statistical testing. The dependent variable was health service utilisation 1 or 2 years following the delivery of the ABI. The predictor variables included age, utilisation behaviour prior to ABI delivery and FAST scores (Single item Q4 and/or Total). Exploratory analyses were run prior to the main inferential statistics presented to determine the influence of single FAST items alone versus the Total score. Analysis of the separate variance explained for each item (FAST 1-3) was very small and insignificant. The only item that performed as well as the Total Score of FAST was Item 4.

\subsection{Information and ethical governance}

NHS Fife Caldicott Guardian approval for this secondary data analysis study was obtained on the $16^{\text {th }}$ July 2014 . We were also advised not to seek for ethics approval. 


\subsection{Results}

\subsection{Sample characteristics}

Raw data taken from ABI dataset, spanning 2008-2011, was collated into a database. A total of 266,783 A\&E episodes were recorded at the two A\&E sites between 2008-2011 (ISD Scotland, 2011). Of this number, 1,824 were alcohol-related episodes, which were based on primary and secondary diagnoses by ICD-10 code. A total of 1929 patients had received an ABI. The 105 additional patients receiving the ABI were due to their self-reported level of alcohol consumption triggering the ABI. On closer inspection of the data, $10.4 \%$ had received more than one $\mathrm{ABI}(\mathrm{N}=198)$, which were removed to enable a focus on the effect of a single ABI. A further 27 cases were deleted due to missing data (gender), resulting in a total of 1704 participants included in the sample.

The majority of participants were white males, with a mean age of 47 years $(S D=15.57)$. A mean SIMD score of 4.31 (SD 2.41) indicated that those who received the ABI resided in more deprived areas (Table 1).

Those who achieve a score above 3 on the FAST were deemed hazardous drinkers (Hodgson et al. 2002). Participants who had received the ABI obtained a mean score of 6.31 (SD 5.13), signifying a heavy pattern of alcohol consumption.

\subsection{Health service utilisation}

Significant decreases in A\&E attendance were found at both one and two years post-ABI $(p<$ .001) (Table 2 and Supplementary Table 2). Of interest on inspection of means was the raised use of out- and in-patient services one year post-ABI. Further detailed analyses (Supplementary Table 2) were conducted separately for both A\&E sites (Site $1 \mathrm{n}=823$, and Site $2 \mathrm{n}=881$ ) and 
demonstrated support for these findings presented in Table 2. There was a strong consistency of significant effects across the two sites $(4 / 22$ i.e. $88 \%$ agreement of $p$ 's $<0.05)$.

\subsection{A\&E attendance}

Older individuals were less likely to attend $\mathrm{A} \& \mathrm{E}$ at one year following the $\mathrm{ABI}(b=-0.011$; $\exp [b]=\mathrm{OR}=0.981$ (Table 3). As expected, patients were almost twice as likely to visit A\&E if they had attended before $(b=0.581$; exp $[b]=\mathrm{OR}=1.946)$. Level of concern for an individual regarding their alcohol consumption resulted in greater likelihood of them attending $\mathrm{A} \& \mathrm{E}$ at both one and two years $(b=0.299$; exp $[b]=\mathrm{OR}=1.349)(b=0.175$; $\exp$ $[b]=\mathrm{OR}=1.191)$. Total FAST score predicted A\&E attendance at one year post-ABI $(b=$ $0.052 ; \exp [b]=\mathrm{OR}=1.053)$. FAST $1-3$ were excluded as they were redundant variables (FAST 1-3) (Table 3).

\subsection{Comparison of health service utilisation across the region}

Delivery of the ABI was conducted using the same team across the two hospitals. The Intraclass Correlation Coefficient (ICC) indicated very little variance when controlling for clustering across sites (Supplementary Table 2). Consequently, this would suggest that the delivery of the ABI by regular allocated members of staff was standardised across A\&E departments.

\subsection{Discussion}

\subsection{Effect of ABI}

Attendance to A\&E significantly decreased following ABI delivery, at both one and two years. However due to the design of the study, it is uncertain as to whether this effect was solely due to intervention content, or as a result of direct contact with a specialist in the 
addiction field. A number of systematic reviews have evidenced the effectiveness of the ABI in reducing alcohol consumption among hazardous and harmful drinkers (O’Donnell et al. 2014), although there is limited evidence regarding brief interventions delivered within emergency care settings (Nilsen et al. 2008). Heather (1986) suggests that personal contact with change agents tend to be more effective than self-help procedures, thus the discussion of alcohol consumption with an addiction trained nurse may have prompted reconsideration of current behaviour.

Over half of the study population reported being in treatment for alcohol (67\%), which is very high for an opportunistic screening programme. This could perhaps be due to the setting of intervention delivery, as there is an increased likelihood of issues with alcohol being presented at A\&E. Treatment was self-reported at the point of ABI delivery, and consisted of various services and third sector organisations, including Alcohol Anonymous and local nonstatutory counselling services.

It has been noted that $\mathrm{ABI}$ delivery within emergency departments can be hampered by a number of constraints, including a perceived lack of time and a limited number of professionals able to administer the intervention (Johnson et al. 2010). However, it has been proposed that brief interventions should be delivered at the primary health care level, and initiated as part of disease management for comorbid conditions (Ornstein et al. 2013; Rehm et al. 2015) rather than conducted by primary health care physicians. Embedding dedicated members of staff within A\&E departments to deliver the intervention has shown to increase the efficacy of the ABI in this and recent studies (Corbain et al. 2011, Platt et al. 2016). The two may have been enhanced by the standardised delivery of the intervention across $A \& E$ 
departments, as the Intraclass Correlation Coefficient (ICC) indicated very little variance when controlling for clustering across sites.

As expected, previous health service utilisation was predictive of later health service use, a possible indicator of the 'revolving door' patient phenomenon, whereby individuals attain a high frequency of hospitalisations, commonly found amongst psychiatric (Botha et al. 2010; Sylva et al. 2009) and surgical (Reddy et al. 2009) patients. The significant increase in outpatient and inpatient admissions at one year may be indicative of the patient's initial A\&E visit requiring further planned treatment. Through implementing the $\mathrm{ABI}$ during an $\mathrm{A} \& \mathrm{E}$ visit, and signposting to services if appropriate, may serve as a 'teachable moment' (Williams et al. 2005). The educational input would highlight the risks associated with hazardous drinking, and reduce this 'revolving door' phenomenon. However, evidence also suggests that high users of emergency department services are also high users of non-emergency department services, indicating that patient-level factors, such as disease burden, are important drivers of frequent emergency department use (Hansagi et al. 2001; LaCalle and Rabin, 2010).

The total FAST score predicted attendance to A\&E one year following the ABI intervention. As a brief screening tool, this is a highly effective way of identifying those who are drinking hazardously in a short space of time, providing support for previous research suggesting that FAST is more appropriate for use in busy clinical settings than lengthier assessments such as AUDIT (Jones, 2011). More specifically, item 4 on the FAST tool was found to be predictive of later patient health service utilisation, at one and two years. Attitudes and subjective norms are argued to be strong predictors of alcohol consumption and behaviour (Cooke et al. 2016; Glassman et al. 2010). Subsequently, it would appear that this construct 
tapping into a societal view of the individual's behaviour enables the individual to admit that their alcohol consumption has become an issue. Although this particular population group has a significant number of those already in treatment $(67 \%)$, it may be that contact with A\&E clinical staff had greater impact upon reduced service use.

\subsection{Strengths and Limitations}

\subsubsection{Methodology}

Although the FAST is a self-reported instrument, the observational nature of this study using routine utilisation attendances and service record data meant that we were not reliant upon patient self-report data. Consequently, the findings were robust with no response bias. We were reassured that many of the findings were consistent across both A\&E sites. However, there may be biases related to the routine data collected, e.g., diagnoses and chart recording practices. There may also be concerns relating to the exclusion of service settings outside the region (i.e., could people have received services that are not captured in this analysis) to the extent that mobility is related to social deprivation and health, thus exclusion may bias the results. We are aware of the ecological fallacy, that is not every person residing inside a disadvantaged area is deprived and conversely many low resourced people reside out of deprived areas, hence the use of the SIMD indicator as a proxy for deprivation includes some error. Furthermore, conclusions must be treated with caution, as the causal effect of reduced A\&E visits cannot be established. The study did not include a control group, and we were unable to use a constructed control group as we only had access to patient information data who had received an ABI. Therefore the significant effects found between pre and post $\mathrm{ABI}$ utilisation may be explained by A\&E care supplementary to the ABI. From anecdotal reports from $A \& E$ staff however the specific attention devoted to alcohol prevention and advice was minimal prior to $\mathrm{ABI}$ implementation. The findings are not generalisable to a more severe, 
clinical population, as $10.4 \%$ of subjects $(\mathrm{N}=198)$ who received more than one ABI were removed to enable a focus on the effect of a single ABI. Rather, the findings are applicable to the predominant category of patient included in the sample, namely white middle-aged men. Finally there was no censoring of deceased individuals which might have overestimated the reduction in health care utilisation. Future informatics studies should also link with mortality $\mathrm{CHI}$ or equivalent registered datasets.

\subsubsection{Informatics}

All of the health-related data available to us from the database were included to provide the opportunity of identifying substantive variables. The risk of over inclusion and finding associations by chance was considered acceptable in this first published report to assist future study designs. Linking data was included to improve the quality and integrity of the data already being collected (Christen and Goiser 2007), thus providing confidence in the data. The costs of collection, storage and governance of this data can be a limiting factor.

\subsection{Future directions}

Further data linkage studies and a cluster randomised controlled trial conducted throughout Scotland or elsewhere would be valuable to identify if similar trends exist. Additionally, a more detailed prospective health economic analysis would highlight the financial benefit gained from delivering the $\mathrm{ABI}$, and emphasise the importance of this particular intervention being delivered throughout services.

\subsection{Public health and clinical implications}

The FAST produced significant findings, predicting attendance to A\&E two years following the intervention. Already deemed the quickest measure to implement in clinical settings, this 
has the potential for exciting development in research regarding societal level of concern for an individual's reported alcohol intake. Consequently, exploring the effect of this screening tool, particularly item 4 would be of great potential benefit to enhance application in clinical settings.

\subsection{Conclusions}

Using a health data linked informatics methodology this study identified the value of Alcohol

Brief Intervention within emergency departments. Additionally Question 4 of the FAST Questionnaire is predictive of A\&E attendance at one and two years after the ABI.

\subsection{Declaration of Interests}

None

\subsection{Acknowledgements}

Data collection and analysis this project was supported by the Health Informatics Centre, Farr Institute (Dundee). In addition financial assistance was provided by NHS Fife Research and Development Department, NHS Fife Addiction Services and NHS Education for Scotland. We would also like to thank NHS Fife A\&E service management and staff, and NHS Fife Addiction Services staff who delivered the ABI at the A\&E Departments in Victoria and Queen Margaret Hospitals. Without their contribution and expertise this research would not have been possible. 


\subsection{References}

Babor, T.F., McRee, B.G., Kassebaum, P.A., Grimaldi, P.L., Ahmed, K., Bray, J., 2007. Screening, Brief Intervention, and Referral to Treatment (SBIRT) toward a public health approach to the management of substance abuse. Subst Abus. 28(3), 7-30.

Babor, T.F., Ritson, E.B., Hodgson, R.J. 1986. Alcohol-related problems in the primary health care setting: a review of early intervention strategies. BJA. 81(1), 23-46.

Bien, T. H., Miller, W. R. and Tonigan, J. S., 1993. Brief interventions for alcohol problems: a review. Addiction, 88(3), 315-335.

Botha, U.A., Koen, L., Joska, J.A., Parker, J.S., Horn, N., Hering, L.M., Oosthuizen,P.P., 2010. The revolving door phenomenon in psychiatry: comparing low-frequency and high-frequency users of psychiatric inpatient services in a developing country. Soc Psych and Psych Epid. 45(4), 461-468.

Bray, J., Cowell, A., Hinde, J., 2011. A systematic review and meta-analysis of health care utilization outcomes in alcohol screening and brief intervention trials. Med Care. 49(3), 287.

Carver, C.S., Scheier, M.F., 1998. On the Self-Regulation of Behavior. New York: Cambridge University Press.

Cherpitel, C.J., 2007. Alcohol and injuries: a review of international emergency room studies since 1995. Drug Alcohol Rev. 26(2), 201-214. 
Cooke, R., Dahdah, M., Norman, P., French, D.P., 2016. How well does the theory of planned behaviour predict alcohol consumption? A systematic review and meta analysis. Health Psychol Rev. 10(2), 148-167.

Christen, P., Goiser, K., 2007. Quality and complexity measures for data linkage and Deduplication, in: Christen, P., Goiser, K (Eds), Quality Measures in Data Mining, Springer: Heidelberg, pp. 127-151.

Cobain, K., Owens, L., Kolamunnage-Dona, R., Fitzgerald, R., Gilmore, I., Pirmohamed, M., 2011.Brief interventions in dependent drinkers: a comparative prospective analysis in two hospitals. Alcohol Alcoholism 46(4), 434-440.

Drummond, C., Deluca, P., Coulton, S., Bland, M., Cassidy, P., Crawford, M., Dale, V., Gilvarry, E., Godfrey, C., Heather, N., McGovern, R., Myles, J., Newbury-Birch, D., Oyefeso. A., Parrott, S., Patton, R., Perryman, K., Phillips, T., Shepherd, J., Touquet, R., Kaner ,K, (2014). The effectiveness of alcohol screening and brief intervention in emergency departments: A multicentre pragmatic cluster randomized controlled trial. PLoS ONE 9(6), Available at e99463. https://doi.org/10.1371/journal.pone.0099463.

Dunn, C., Deroo, L. and Rivara, F. P., 2001. The use of brief interventions adapted from motivational interviewing across behavioural domains: a systematic review. Addiction 96(12), 1725-1742.

Glassman, T., Braun, R.E., Dodd, V., Miller, J.M., Miller, E.M., 2010. Using the theory 
of planned behavior to explain the drinking motivations of social, high-risk, and extreme drinkers on game day. J Commun Health. 35(2), 172-181.

Gollwitzer, P.M., Sheeran, P., 2006. Implementation intentions and goal achievement: A meta-analysis of effects and processes. Adv Exp Soc Psychol. 38, 69-119.

Hansagi, H., Olsson, M., Sjöberg, S., Tomson,Y., Goransson, B.A., 2001. Frequent use of the hospital emergency department is indicative of high use of other health care services. Ann Emerg Med. 37(6), 561-567.

Havard, A., Shakeshaft, A., Sanson-Fisher, R., 2008. Systematic review and meta-analyses of strategies targeting alcohol problems in emergency departments: interventions reduce alcohol-related injuries. Addiction 103(3), 368-376.

Heather, N., 2011. Developing, evaluating and implementing alcohol brief interventions in Europe. Drug Alcohol Rev. 30(2), 138-147

Heather, N., 1986. Minimal treatment interventions for problem drinkers in: Edwards, G (Ed), Current Issues in Clinical Psychology, Plenum Press: London, pp.171-86.

Hodgson, R., Alwyn, T., John, B., Thom, B., Smith, A., 2002.The FAST alcohol screening test. Alcohol Alcoholism. 37(1), 61-66. 
Information Services Division (ISD) Scotland. 2014. Alcohol-related Hospital Statistics Scotland 2012/13[accessed September 23, 2017]. Available at:

http://www.isdscotland.org/Health-Topics/Drugs-and-Alcohol

Misuse/Publications/2014-02-25/2014-02-25-ARHS2012-13-Report.pdf

Information Services Division (ISD) Scotland. 2011. Emergency Department Activity:

Statistics [accessed on November 24, 2017]. Available at:

http://www.isdscotland.org/Health-Topics/Emergency-Care/EmergencyDepartment Activity/Statistics/

Johnson, M., Jackson, R., Guillaume, L., Meier, P., Goyder, E., 2011. Barriers and facilitators to implementing screening and brief intervention for alcohol misuse: a systematic review of qualitative evidence. J Public Health. 33(3), 412-421.

Jones, L.A., 2011. Systematic review of alcohol screening tools for use in the emergency department. Emergen Med. 28(3), 182-191.

Kaner, E.F., Beyer, F., Dickinson, H.O., Pienaar, E., Campbell, F., Schlesinger, C., Heather N., Saunders, J., Burnand, B., 2007. Effectiveness of brief alcohol interventions in primary care populations. Cochrane Database Systematic Review 18; (2):CD004148.

Kaner, E.F.S., 2016. Screening and brief alcohol intervention in primary care-a perfect fit or around peg in a square hole? 13th conference of INEBRIA 
22-23th September 2016 Lausanne (Switzerland). [Accessed 25 ${ }^{\text {th }}$ January 2018]. Available at http://inebria.net/wp-content/uploads/2016/10/Plenary-session-1-Eileen-

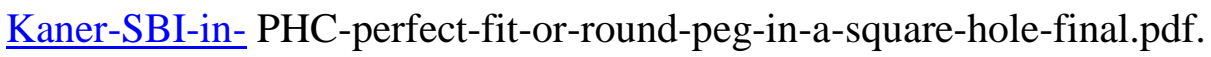

LaCalle, E., Rabin, E., 2010. Frequent users of emergency departments: the myths, the data, and the policy implications. Ann Emerg Med. 56(1), 42-48.

McQueen, J., Howe, T.E., Allan, L., Mains, D., Hardy, V., 2011.. Brief interventions for heavy alcohol users admitted to general hospital wards. Cochrane Database of Systematic Reviews, 8; CD005191.

Michie, S., Whittington, C., Hamoudi, Z., Zarmani, F., Gillian, T., Robert, W., 2012. Identification of behaviour change techniques to reduce excessive alcohol consumption. Addiction 107(8), 1431-1440.

Nilsen, P., Baird, J., Mello, M.J., Nirenberg, T., Woolard, R., Bendtsen, P., Longabaugh, R., 2008. A systematic review of emergency care brief alcohol interventions for injury patients. J Subst Abuse Treat. 35(2), 184-201.

O'Donnell, A., Anderson, P., Newbury Birch, D., Schulte, B., Schmidt, C., Reimer, J., Kaner, E., 2014.The impact of brief alcohol interventions in primary healthcare: a systematic review of reviews. Alcohol Alcoholism. 49(1), 66-78.

Ornstein, S.M., Miller, P.M., Wessell, A.M., Jenkins, R.G., Nemeth, L.S., Nietert, P.J., 
2013. Integration and sustainability of alcohol screening, brief intervention, and pharmacotherapy in primary care settings. J Stud Alcohol Drugs.74(4), 598-604.

Platt,L., Melendez-Torres,G.J., O’Donnell,A., Bradley,J., Newbury-Birch,D., Kaner,E., Ashton,C., 2016. How effective are brief interventions in reducing alcohol consumption: do the setting, practitioner group and content matter? Findings from a systematic review and metaregression analysis. BMJ Open [Accessed $20^{\text {th }}$ January 2018] Available at http://dx.doi.org/ 10.1136/bmjopen-2016-011473.

Public Health England. (2013). Alcohol Treatment in England 2012-2013 [Accessed February 12, 2018].Available at: http://www.nta.nhs.uk/uploads/alcohol2012-13.pdf

Reddy, D.M., Townsend, Jr C.M., Kuo, Y.F., Freeman,J.L., Goodwin, J.S., Riall, S.T., 2009. Readmission after pancreatectomy for pancreatic cancer in Medicare patients. J Gastrointest Surg. 13(11), 1963-1975.

Rehm, J., Anderson, P., Manthey, J., Shield, K.D., Struzzo, P., Wojnar, M., Gual, A., 2015. Alcohol use disorders in primary health care: what do we know and where do we go? Alcohol Alcoholism. 51(4), 422-427.

Rehm, J., Zatonski, W., Taylor, B., Anderson, P., 2011. Epidemiology and alcohol policy in Europe. Addiction 106, 11-19. 
Saunders, J.B., Aasland, O.G., Babor, T.F., de la Fuente, J.R., Grant, M., 1993. Development of the alcohol use disorders identification test (AUDIT): WHO collaborative project on early detection of persons with harmful alcohol consumption-II. Addiction 88(6), 791-804.

School of Medicine, University of Dundee. 2015. Standard Operating Procedures (SOPs) [accessed on September 2, 2017]. Available at:

http://medicine.dundee.ac.uk/standard-operating-procedures-sops

Scottish Government. 2015. Local Delivery Plan Standard: Alcohol Brief

Interventions National Guidance: 2015-16 [accessed 11th February 2018].Available at:

http://www.show.scot.nhs.uk/wp-content/uploads/2015/06/Alcohol-Brief-Interventions

ABI-National-Guidance-2015-16.pdf

Scottish Government. 2014. Alcohol Brief Interventions: HEAT Standards [Accessed December 4, 2017]. Available at:

http://www.scotland.gov.uk/About/Performance/scotPerforms/partnerstories/NHSScotln $\underline{\text { d performance/alcoholbriefinterventionsStandard }}$

Scottish Health Survey. 2014. A National Statistics Publication for Scotland 2014:

Alcohol [Accessed November 20, 2017]. Available at: http://www.gov.scot/Resource/0048/00485587.pdf 
Scottish Index of Multiple Deprivation (SIMD). 2012. Scottish Index of Multiple Deprivation [accessed on November 10, 2017]. Available at: http://www.gov.scot/Topics/Statistics/SIMD

Scottish Trauma Audit Group. 2006. NHSQIS/STAG: Scottish Emergency Department Alcohol Audit (SEDAA)_[Accessed January 29, 2018]. Available at: http://www.stag.scot.nhs.uk/Projects/Alcohol.html

Sylva, N.C., Bassani, D.G., Palazzo, L.S., 2009. A case-control study of factors associated with multiple psychiatric readmissions. Psychiat Serv. 60(6), 786-791.

Thomas, E., Degenhardt, L., Alati, R., Kinner,S., 2014. Predictive validity of the AUDIT for hazardous alcohol consumption in recently released prisoners. Drug Alcohol Depen. 134, 322-329.

Wojnar, M., Jakubczyk, A., 2014. Brief interventions for hazardous and harmful alcohol consumption in accident and emergency departments. Frontiers in Psychiatry [Accessed $10^{\text {th }}$ January 2018] Available at: doi: 10.3389/fpsyt.2014.00152.

Williams, S., Brown, A., Patton, R., Crawford, M.J., Touquet, R., 2005. The half-life of the 'teachable moment' for alcohol misusing patients in the emergency department. Drug Alcohol Depen. 77(2), 205-208. 
World Health Organisation. 2010. European Status Report on Alcohol and Health 2010 [Accessed June 20, 2017]. Available at: http://www.euro.who.int/data/assets/pdf file/0004/128065/e94533.pdf

World Health Organisation. 2001. AUDIT - The Alcohol Use Disorders Identification Test: Guidelines for use in primary care. $2^{\text {nd }}$ edition Geneva: WHO. 
Figures legends

Figure 1: Flowchart of inclusion and exclusion of cases

Figure 2: ABI dataset linked with core health related datasets 
Figure 1:



$A \& E=$ Accident and Emergency; $N=$ number; FAST=Fast Alcohol Screening Test 


\section{Figure 2:}

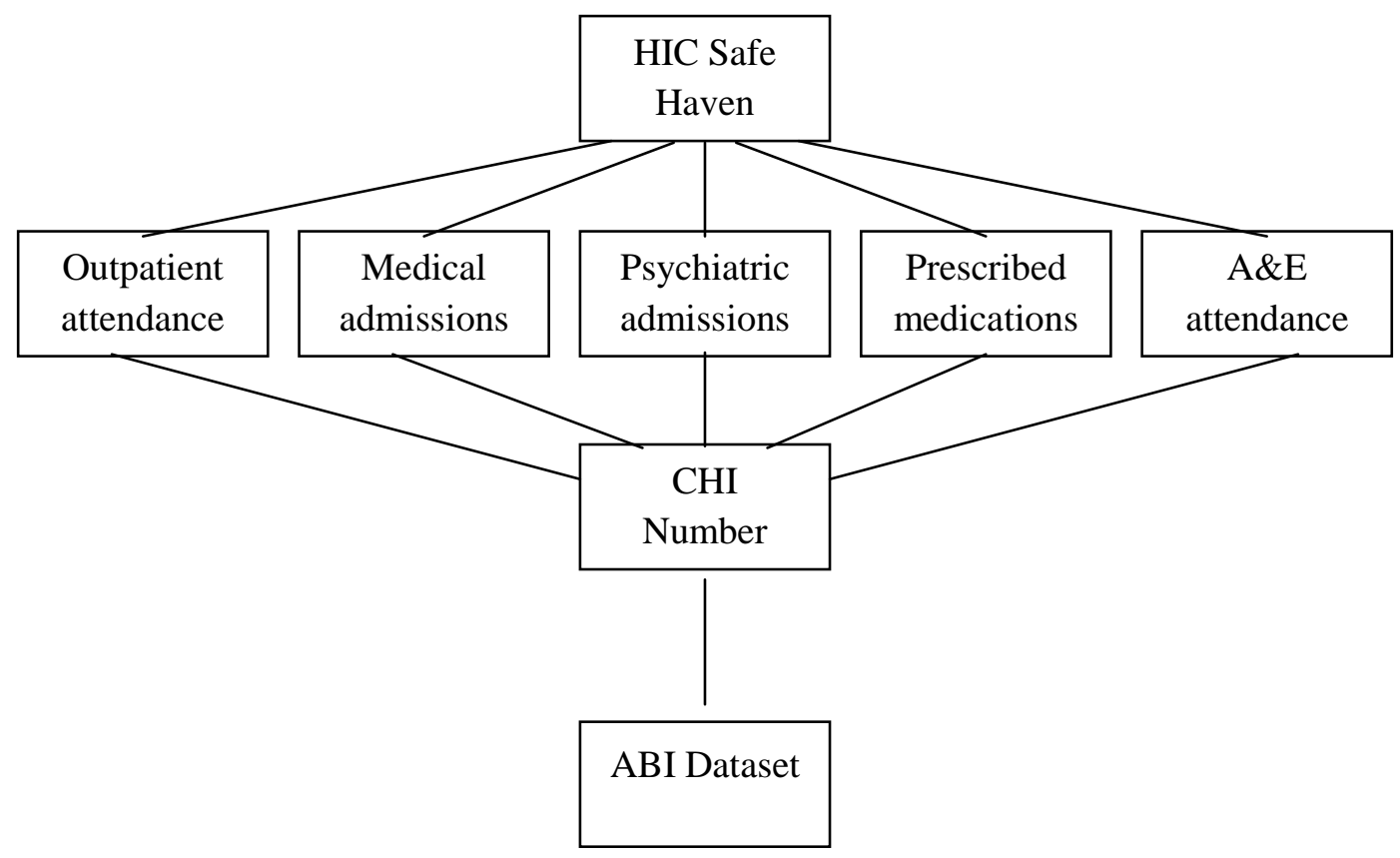

$C H I=C o m m u n i t y ~ H e a l t h$ Index; $A \& E=$ Accident and Emergency Department; HIC= Health Informatics Centre, University of Dundee; $A B I=A /$ cohol Brief Interventions 
Tables

\begin{tabular}{lcc}
\hline Characteristics & M & SD \\
& & \\
\hline Age in years & 47.16 & 15.57 \\
Male (\%) & 64.9 & - \\
Female (\%) & 35.1 & - \\
SIMD & 4.31 & 2.41 \\
Ethnicity & & \\
White (\%) & 99.3 & - \\
Mixed (\%) & 0.1 & - \\
Asian, Asian Scottish, Asian British & 0.1 & - \\
(\%) & & - \\
Other ethnic background (\%) & 0.5 & \\
Already in treatment for alcohol & & - \\
No (\%) & 34.8 & - \\
Yes (\%) & 65.2 & \\
Alcohol service referral & & - \\
No (\%) & 82.6 & - \\
Yes (\%) & 17.4 & \\
FAST & & \\
Average weekly alcohol consumption* & 57.56 & 79.16 \\
FAST Q1 & 2.64 & 1.28 \\
FAST Q2 & 1.06 & 1.44 \\
FAST Q3 & 1.01 & 1.48 \\
FAST Q4 & 0.73 & 0.91 \\
Total FAST score & 6.31 & 5.13 \\
\hline
\end{tabular}

SIMD = Scottish Index of Deprivation; FAST= Fast Alcohol Screening Test; $Q=$ FAST Question number; * = Units of alcohol

Table 1: Sample characteristics $(\mathrm{N}=1704)$ reported at delivery of Alcohol Brief Interventions (ABI) 


\begin{tabular}{|c|c|c|c|}
\hline $\begin{array}{l}\text { Health Service Utilisations } \\
(N=1704)\end{array}$ & $\begin{array}{c}\text { Pre } A B I \\
1 \text { year } \\
\text { (Mean) }\end{array}$ & $\begin{array}{c}\text { Post-ABI } \\
1 \text { year } \\
\text { (Mean) }\end{array}$ & $\begin{array}{c}\text { Post-ABI } \\
2 \text { years } \\
(\text { Mean) }\end{array}$ \\
\hline $\mathrm{A} \& \mathrm{E}$ & .53 & $.44 * * *$ & $.33 * * *$ \\
\hline Outpatient & .42 & $.57 * * *$ & .43 \\
\hline Inpatient & .05 & $.08 * *$ & .05 \\
\hline
\end{tabular}

${ }^{*} p<0.05$. ${ }^{* *} p<0.005$. ${ }^{* * *} p<0.001$. Significant test results for each service shown on comparing Pre-ABI 1 year utilisation with subsequent Post-ABI 1 and 2 year utilisation applying non-independent $t$-Tests.

Table 2: Mean levels of patients' health service use (A\&E, outpatient, inpatient) one year before the delivery of the ABI, and one and two year post-ABI. 


\begin{tabular}{lcccccc}
\hline Predictor variable & \multicolumn{3}{c}{$\begin{array}{c}\text { A\&E Post-ABI } \\
\text { 1 year }\end{array}$} & \multicolumn{3}{c}{$\begin{array}{c}\text { A\&E Post-ABI } \\
\text { 2 years }\end{array}$} \\
\cline { 2 - 8 } & $\boldsymbol{B}$ & $\boldsymbol{S E} \boldsymbol{B}$ & $\boldsymbol{E x p}(\boldsymbol{B})$ & $\boldsymbol{B}$ & SE B & $\boldsymbol{E x p}(\boldsymbol{B})$ \\
\hline Age & $-.011^{* *}$ & .003 & .989 & -.008 & .019 & .992 \\
A\&E Attendance & & & & & & \\
Previous (2 years) & $.666^{* * *}$ & .110 & 1.973 & $.581 * * *$ & .115 & 1.946 \\
Previous (1 year) & $.668^{* * *}$ & .108 & 1.954 & $.467 * * *$ & .117 & 1.951 \\
Post (1 year) & - & - & - & $.719 * * *$ & .112 & 2.052 \\
FAST Q4 & $.299^{* * *}$ & .086 & 1.349 & $.175^{*}$ & .053 & 1.191 \\
Total FAST score & $.052 * * *$ & .010 & 1.053 & - & - & 1.020
\end{tabular}

Note: The dependent variable in this analysis is attendance coded as $0=$ no admissions and $1=$ admissions. Controlled for age, gender and SIMD.; ${ }^{*} p<0.005$. ${ }^{* *} p<0.001$. ${ }^{* * *} p<0.000$

Table 3: Logistic regression analysis of attendance to $A \& E, 1$ and 2 years following delivery of the ABI 


\section{Supplementary Tables}

For the following questions please circle the answer which best applies.

$1 \mathrm{drink}=1 / 2$ pint of beer or 1 glass of wine or 1 single spirits

1. MEN: How often do you have EIGHT or more drinks on one occasion?

WOMEN: How often do you have SIX or more drinks on one occasion?

$\begin{array}{ccccc}\text { Never } & \text { Less than monthly } & \text { Monthly } & \text { Weekly } & \begin{array}{c}\text { Daily or almost } \\ \text { daily }\end{array} \\ 0 & 1 & 2 & 3 & 4\end{array}$

2. How often during the last year have you been unable to remember what happened the night before because you had been drinking?

$\begin{array}{ccccc}\text { Never } & \text { Less than monthly } & \text { Monthly } & \text { Weekly } & \begin{array}{c}\text { Daily or almost } \\ \text { daily }\end{array} \\ 0 & 1 & 2 & 3 & 4\end{array}$

3. How often during the last year have you failed to do what was normally expected of you because of drinking?

$\begin{array}{ccccc}\text { Never } & \text { Less than monthly } & \text { Monthly } & \text { Weekly } & \begin{array}{c}\text { Daily or almost } \\ \text { daily }\end{array} \\ 0 & 1 & 2 & 3 & 4\end{array}$

4. In the last year has a relative or friend, or a doctor or other health worker been concerned about your drinking or suggested you cut down?

\begin{tabular}{ccc} 
No & Yes, on one occasion & Yes, on more than one occasion \\
0 & 2 & 4 \\
\hline
\end{tabular}

Table 1: Fast Alcohol Screening Test (FAST) 


\begin{tabular}{|c|c|c|c|c|}
\hline \multirow[t]{2}{*}{ Predictor Variable } & \multicolumn{2}{|c|}{$\begin{array}{l}\text { A\&E site } 1 \\
(N=823)\end{array}$} & \multicolumn{2}{|c|}{$\begin{array}{c}\text { A\&E site } 2 \\
(N=\mathbf{8 8 1})\end{array}$} \\
\hline & $\bar{B}$ & $\operatorname{Exp}(B)$ & $\bar{B}$ & $\operatorname{Exp}(B)$ \\
\hline \multicolumn{5}{|l|}{$\begin{array}{l}\text { All Medical Outpatient Attendance } \\
\text { (Post-ABI } 1 \text { year) }\end{array}$} \\
\hline Age & $0.012 *$ & 1.012 & $0.017 * * *$ & 1.017 \\
\hline Outpatient attendance Pre 2 years & $0.492 * *$ & 1.636 & $0.776 * * *$ & 2.172 \\
\hline Outpatient attendance Pre 1 year & $0.838 * * *$ & 2.311 & $1.557 * * *$ & 4.744 \\
\hline \multicolumn{5}{|l|}{$\begin{array}{l}\text { All Medical Outpatient Attendance } \\
\text { (Post-ABI } 2 \text { years) }\end{array}$} \\
\hline Gender & $0.488 * *$ & 1.628 & $0.513 * *$ & 1.670 \\
\hline Outpatient attendance Pre 2 years & $0.343^{*}$ & 1.409 & $0.816^{* * *}$ & 2.261 \\
\hline Outpatient attendance Pre 1 year & $0.661 * * *$ & 1.937 & $0.350 *$ & 1.419 \\
\hline Outpatient attendance Post 1 year & $1.332 * * *$ & 3.340 & $1.31 * * *$ & 3.099 \\
\hline \multicolumn{5}{|l|}{$\begin{array}{l}\text { All medical Inpatient Admissions } \\
\text { (Post-ABI } 1 \text { year) }\end{array}$} \\
\hline Age & $0.043 * * *$ & 1.044 & $0.054 * * *$ & 1.056 \\
\hline Total FAST score & 0.042 & 1.042 & $0.077 * *$ & 1.080 \\
\hline \multicolumn{5}{|l|}{$\begin{array}{l}\text { All Medical Inpatient Admissions } \\
\text { (Post-ABI } 2 \text { years) }\end{array}$} \\
\hline Age & $0.037 * * *$ & 1.038 & 0.014 & 1.014 \\
\hline Total FAST score & $0.084 *$ & 1.088 & $0.60 *$ & 1.062 \\
\hline \multicolumn{5}{|l|}{$\begin{array}{l}\text { Inpatient Psychiatric admissions } \\
\text { (Post-ABI } 1 \text { year) }\end{array}$} \\
\hline Psychiatric admissions Pre 1 year & $1.754 * *$ & 5.779 & $3.742 * * *$ & 42.203 \\
\hline \multicolumn{5}{|l|}{$\begin{array}{l}\text { Inpatient Psychiatric admissions } \\
\text { (Post-ABI } 2 \text { years) }\end{array}$} \\
\hline Psychiatric admissions Post 1 year & $2.292 * * *$ & 9.894 & $2.521 * * *$ & 12.440 \\
\hline Total FAST score & 0.090 & 1.094 & $0.122 *$ & 1.130 \\
\hline \multicolumn{5}{|l|}{$\begin{array}{l}\text { A\&E Attendance (Post-ABI } \\
1 \text { year) }\end{array}$} \\
\hline A\&E attendance Pre 2 years & $0.706 * * *$ & 2.026 & $0.648 * * *$ & 1.911 \\
\hline A\&E attendance Pre 1 year & $0.508 * *$ & 1.662 & $0.830 * * *$ & 2.293 \\
\hline Total FAST score & $0.050 * *$ & 1.052 & $0.054 * * *$ & 1.055 \\
\hline \multicolumn{5}{|l|}{$\begin{array}{l}\text { A\&E Attendance (Post-ABI } \\
2 \text { years) }\end{array}$} \\
\hline Age & 0.001 & 1.001 & $-0.018 * *$ & 0.982 \\
\hline A\&E attendance Pre 2 years & $0.816^{* * *}$ & 2.261 & $0.381 *$ & 1.463 \\
\hline A\&E attendance Pre 1 year & $0.358 *$ & 1.431 & $0.624 * * *$ & 1.866 \\
\hline A\&E attendance Post 1 year & $0.748 * * *$ & 2.114 & $0.675 * * *$ & 19.65 \\
\hline \multicolumn{5}{|l|}{$\begin{array}{l}\text { Prescribed Medication (Post-ABI } \\
1 \text { year) }\end{array}$} \\
\hline Total FAST Score & $0.065 * *$ & 1.067 & 0.029 & 1.029 \\
\hline
\end{tabular}

Table 2: Logistic regression analysis of health service utilisation 1 and 2 years following the delivery of the ABI 